\title{
Crescimento de mudas de cedro-rosa em diferentes substratos
}

\author{
Lúcio dos Reis Oliveira', Sebastião Ferreira de Lima², Ana Paula Leite de Lima² \\ ${ }^{1}$ Instituto Mineiro de Agropecuária, Rua Arthur Botelho, s/nº, Colégio Agrícola, CEP 38740-000, Patrocínio, MG, Brasil \\ ${ }^{2}$ Universidade Federal de Mato Grosso do Sul, Campus CPCS, Rodovia MS 306, Estrada do Pasto Ruim, CP 112, CEP 79560-000, Chapadão do Sul, MS, Brasil
}

"Autor correspondente:

lucioima@yahoo.com.br

Termos para indexação:

Propagação sexuada

Espécies nativas

Compostos orgânicos

Index terms:

Sexual propagation

Native species

Organic compounds

Histórico do artigo:

Recebido em 25/10/2013

Aprovado em 11/08/2014

Publicado em 10/10/2014

doi: 10.4336/2014.pfb.34.79.605
Resumo - A produção de espécies nativas demanda o conhecimento sobre melhores substratos e o consequente crescimento inicial dessas mudas. O objetivo deste trabalho foi de avaliar o crescimento inicial de mudas de cedro-rosa (Cedrela fissilis Vell.) em diferentes substratos e seu estabelecimento inicial em campo. O experimento foi instalado em duas etapas. A primeira, foi conduzida em viveiro em delineamento em blocos casualizados, com quatro repetições. Cada parcela foi composta por quatro mudas em sacos plásticos. Os tratamentos foram constituídos de oitos diferentes substratos: T1 (areia+solo+esterco 1:1:1); T2 (areia+solo+Plantmax 1:1:1); T3 (solo+esterco 1:1); T4 (solo+Plantmax 1:1); T5 (solo+esterco 2:1); T6 (solo+Plantmax 2:1); T7 (solo+areia 1:1) e T8 (solo). Avaliou-se a altura das plantas, diâmetro do colo, número de folhas, diâmetro de copa e índices de qualidade. Verificou-se que o melhor crescimento e qualidade de mudas de cedro-rosa produzidas em viveiro foram obtidos com os tratamentos areia+solo+esterco (1:1:1), solo+esterco (2:1) e solo+esterco (1:1). Os substratos utilizados na produção de mudas em viveiro influenciaram o crescimento inicial de mudas de cedro-rosa em campo, sendo que os melhores resultados observados para o crescimento em altura e diâmetro do caule em viveiro se mantêm após o plantio no campo.

\section{Growth of cedar seedlings at different substrates}

\begin{abstract}
The production of native species requires the knowledge of the best substrates and subsequent initial growth of these seedlings. This work aimed to evaluate the initial growth cedar seedlings (Cedrela fissilis Vell.) in different substrates and their initial establishment in field. The experiment was conducted in two stages. The first was conducted in nursery in a randomized block design with four replications. Each plot consisted of four seedlings in plastic bags. The treatments consisted of eight different substrates: T1 (sand+ soil+manure 1:1:1), T2 (sand+soil+Plantmax 1:1:1), T3 (soil+manure 1:1), T4 (soil+Plantmax ${ }^{\circledR}$ 1:1), T5 (soil+manure 2:1), T6 (soil+Plantmax 2:1), T7 (soil+sand 1:1) and T8 (soil). Plant height, stem diameter, number of leaves, canopy diameter and quality indexes were evaluate. It was found that the best growth and quality of cedar seedlings grown in nurseries were obtained with treatments sand+soil+manure (1:1:1), soil+manure $(2: 1)$ and soil+manure $(1: 1)$. The substrates used in the seedlings production in the nursery influence seedling growth cedar in the field, and the best results observed for height growth and stem diameter in nursery remain after planting in the field.
\end{abstract}




\section{Introdução}

Cedrela fissilis Vell., conhecido como cedro-rosa, pertence à família Meliaceae e é uma das espécies florestais mais importantes da América Tropical (Souza et al., 2009). Nativa do Brasil, pode alcançar uma altura de até $35 \mathrm{~m}$ e um diâmetro de tronco de $60 \mathrm{~cm}$ a $90 \mathrm{~cm}$ (Lorenzi, 1992). É naturalmente encontrada nos domínios fitogeográficos da Amazônia, Cerrado e Mata Atlântica, sendo classificada como espécie secundária inicial a secundária tardia. Ocorre em todas as regiões brasileiras, tanto em florestas primárias quanto em secundárias, sendo indicada para uso madeireiro, paisagístico e de recuperação de áreas degradadas (Lorenzi, 1992; Carvalho, 1994; Caires et al., 2011; Stefano et al., 2014).

A necessidade de se conhecer os principais processos que envolvem a formação de mudas de espécies florestais nativas se evidenciou no Brasil, nos últimos anos, principalmente em razão dos incentivos à recomposição de áreas de preservação permanente e à recuperação de áreas degradadas (Rêgo \& Possamai, 2004). Essa crescente demanda por mudas tem exigido pesquisas relacionadas ao uso de substratos, dentre outros aspectos, capazes de proporcionar mudas que apresentem elevadas taxas de crescimento inicial e de sobrevivência após o plantio (Cunha et al., 2005) e, consequentemente, redução nos custos de estabelecimento dessas espécies (Scalon et al., 2011). Segundo Ferreira et al. (2009), a caracterização das condições mais apropriadas para a produção de mudas propicia a busca por fatores favoráveis ao crescimento inicial em campo, colaborando para o aumento da homogeneidade, da sanidade e da redução da mortalidade no plantio. Apesar disso, de acordo com Rego \& Possamai (2004), são escassos os resultados de pesquisa envolvendo estudos sobre aspectos silviculturais e autoecológicos que demonstrem o potencial das espécies em programas de reflorestamento ou de recuperação de áreas degradadas.

Para Cunha et al. (2005), uma das dificuldades enfrentadas por quem trabalha com a produção de mudas de espécies florestais nativas é o crescimento lento de muitas delas, sendo, portanto, essencial a definição de protocolos e estratégias que favoreçam a produção de mudas com qualidade, em menor espaço de tempo e em condições acessíveis aos pequenos e médios produtores rurais, visto ser este o público mais interessado neste tipo de insumo.
O substrato é o meio em que as plantas são cultivadas fora do solo, considerando como sua função primordial promover suporte, funcionando ainda como regulador da disponibilidade de nutrientes e de água (Kämpf, 2000). Os substratos são constituídos por três frações: a física, a química e a biológica. As frações físico-químicas são formadas por partículas minerais e orgânicas, contendo poros que podem ser ocupados por ar e/ou água e, a fração biológica, pela matéria orgânica (Ferreira et al., 2009). Além disso, a qualidade do substrato depende das proporções e dos materiais que compõem a mistura (Dias et al., 2010).

A avaliação de substratos para espécies nativas têmse ampliando, buscando, principalmente, a redução de custo e a melhoria no desenvolvimento e na qualidade das mudas. Assim, enquanto Scalon et al. (2011) utilizaram substratos a base de terra, areia e diferentes proporções de adubo orgânico ou químico, Ferreira et al. (2009) usaram terra, areia e terra, vermiculita, areia e diferentes substratos comerciais, Danner et al. (2007) utilizaram; substrato comercial, terra de mata nativa e vermicomposto, terra de mata nativa, vermicomposto e areia, terra de mata nativa, vermicomposto e vermiculita e vermicomposto, Mesquita et al. (2011) usaram solo e esterco bovino; solo, esterco bovino e areia; solo, esterco bovino e palha de arroz carbonizada; solo, esterco bovino e pó de coco; solo, esterco bovino e vermiculita.

A introdução de componentes alternativos ao solo em diferentes proporções, também têm sido testados, principalmente em razão da necessidade de se reduzir os custos de produção das mudas e aproveitar resíduos que anteriormente seriam descartados. Maranho \& Paiva (2012) testaram diferentes porcentagens de resíduo orgânico de açaí misturado à terra de mata e verificaram que o substrato constituído por $100 \%$ do resíduo de açaí e com terra de mata propiciou maior crescimento das mudas.

Para a produção de mudas de Cedrela fissilis Vell., Oliveira et al. (2008) indicaram substratos à base de húmus de minhoca, casca de amendoim processada e turfa como as mais adequadas, enquanto para Cedrela odorata, Roweder et al. (2012) indicaram o substrato de húmus de minhoca.

Assim, o objetivo desse trabalho foi de avaliar o crescimento inicial de mudas de cedro-rosa em diferentes substratos e seu estabelecimento inicial em campo. 


\section{Material e métodos}

O experimento foi instalado no Município de Patrocínio, MG, na área experimental do Centro Universitário do Cerrado Patrocínio (UNICERP), em duas etapas. A primeira, instalada em agosto de 2009, foi conduzida em viveiro com cobertura e revestimento lateral de sombrite $50 \%$. Adotou-se o delineamento em blocos casualizados, com 4 repetições, perfazendo 32 parcelas. Cada parcela foi composta por quatro mudas, utilizando como recipiente sacos de polietileno $(18 \mathrm{~cm}$ de altura e $9 \mathrm{~cm}$ de diâmetro), comportando 1.144,53 $\mathrm{cm}^{3}$ de substrato, com uma muda de Cedrela fissilis Vell. (cedro-rosa) por recipiente. As sementes utilizadas foram coletadas no Município de Patrocínio, MG, tendo sido semeadas três sementes por recipiente, que iniciaram a germinação aos 18 dias e foram desbastadas aos 54 dias, ficando apenas a muda mais vigorosa por recipiente.

Os tratamentos foram constituídos de oitos diferentes substratos e suas respectivas proporções em volume: T1 (areia+solo+esterco 1:1:1); T2 (areia+solo+Plantmax 1:1:1); T3 (solo+esterco 1:1); T4 (solo+Plantmax 1:1); T5 (solo+esterco 2:1); T6 (solo+Plantmax 2:1); T7 (solo+areia 1:1) e T8 (solo). A análise química dos substratos encontra-se na Tabela 1.
Verifica-se que os substratos apresentaram diferentes características químicas em função de suas composições e que se refletem nos valores das variáveis avaliadas para o cedro-rosa. Exceto os substratos T7 (solo+areia) e T8 (solo), os demais apresentaram maiores valores para matéria orgânica, $\mathrm{Ca}, \mathrm{Mg}, \mathrm{K}, \mathrm{P}$ e N , além de maior CTC e saturação por bases (V\%). O substrato T4 (Solo+substrato 1:1) foi o que apresentou maior teor de matéria orgânica e fósforo.

Nesta primeira etapa, as avaliações foram realizadas aos três e cinco meses após a semeadura. Aos três meses foi avaliada a altura total $(\mathrm{H})$, em centímetros e, o número de folhas (NF) expandidas por muda. Aos cinco meses, foi avaliada a altura total $(\mathrm{H})$, o número de folhas $(\mathrm{NF})$, o diâmetro do colo (D), a massa seca de raiz (MR) e da parte aérea (MPA), em g por muda, obtidas utilizando estufa de circulação forçada de ar a $60^{\circ} \pm 5^{\circ} \mathrm{C}$, até obtenção de massa seca constante. Para a obtenção da MR e MPA, foi utilizada apenas a planta média da parcela. Para a determinação desta, foi calculada a altura média das plantas e utilizada aquela que apresentava o valor de altura mais próximo da média obtida. Além disso, foi avaliada a qualidade das mudas por meio de índices: Altura da parte aérea/diâmetro do caule (H/D), Altura da parte aérea/massa de matéria seca da parte aérea (H/MPA), matéria seca da parte aérea/ matéria seca das raízes (MPA/MR) e índice de qualidade de Dickson (IQD) (Dickson et al., 1960).

Tabela 1. Análise química dos substratos utilizados no experimento de crescimento inicial de mudas de cedro-rosa (Cedrela fissilis Vell.), em Patrocínio, MG.

\begin{tabular}{|c|c|c|c|c|c|c|c|c|}
\hline \multirow{2}{*}{ Características } & \multicolumn{8}{|c|}{ Substratos } \\
\hline & T1 & $\mathbf{T 2}$ & T3 & T4 & T5 & T6 & $\mathbf{T 7}$ & T8 \\
\hline pH em água & 7,5 & 5,90 & 7,60 & 5,80 & 7,30 & 5,90 & 6,10 & 5,90 \\
\hline $\mathrm{H}+\mathrm{Al}\left(\mathrm{Cmolc} \mathrm{dm}^{3}\right)$ & 1,40 & 3,00 & 1,54 & 4,00 & 1,93 & 3,42 & 1,90 & 2,48 \\
\hline $\mathrm{Al}^{+3}\left(\mathrm{Cmolc} \mathrm{dm}^{-3}\right)$ & - & - & - & - & - & - & - & - \\
\hline $\mathrm{Ca}^{+2}\left(\mathrm{Cmolc} \mathrm{dm}^{-3}\right)$ & 2,00 & 2,66 & 2,60 & 3,70 & 2,22 & 2,60 & 0,83 & 1,30 \\
\hline $\mathrm{Mg}^{+2}\left(\right.$ Cmolc $\left.\mathrm{dm}^{-3}\right)$ & 1,19 & 1,34 & 1,61 & 1,98 & 1,24 & 1,31 & 0,21 & 0,78 \\
\hline $\mathrm{K}^{+}\left(\right.$Cmolc $\left.\mathrm{dm}^{-3}\right)$ & 1,75 & 0,57 & 2,45 & 0,90 & 1,84 & 0,66 & 0,15 & 0,25 \\
\hline $\mathrm{P} \mathrm{mg} \mathrm{dm}{ }^{-3}$ & 78,42 & 78,42 & 120,41 & 127,19 & 64,18 & 78,42 & 1,63 & 0,99 \\
\hline M.O. (\%) & 5,43 & 8,22 & 13,97 & 14,90 & 10,28 & 10,57 & 1,29 & 3,00 \\
\hline $\mathrm{N}(\%)$ & 0,27 & 0,41 & 0,69 & 0,74 & 0,51 & 0,53 & 0,06 & 0,15 \\
\hline CTC $\left(\right.$ Cmolc dm $\left.{ }^{-3}\right)$ & 6,34 & 7,57 & 8,26 & 10,58 & 7,23 & 7,99 & 3,09 & 4,81 \\
\hline V $(\%)$ & 78,00 & 60,00 & 81,00 & 62,00 & 73,00 & 57,00 & 39,00 & 48,00 \\
\hline $\mathrm{Ca} / \mathrm{Mg}$ & 1,68 & 1,99 & 1,65 & 1,87 & 1,79 & 1,98 & 3,95 & 1,67 \\
\hline $\mathrm{Ca} / \mathrm{K}$ & 1,14 & 4,64 & 1,08 & 4,13 & 1,20 & 3,93 & 5,41 & 5,19 \\
\hline $\mathrm{Mg} / \mathrm{K}$ & 0,68 & 2,34 & 0,66 & 2,21 & 0,67 & 1,98 & 1,37 & 3,11 \\
\hline
\end{tabular}

$\mathrm{T} 1=$ areia + solo+esterco $(1: 1: 1) ; \mathrm{T} 2=$ areia + solo+substrato $(1: 1: 1) ; \mathrm{T} 3=$ solo+esterco $(1: 1) ; \mathrm{T} 4=$ solo+substrato $(1: 1) ; \mathrm{T} 5=$ solo+esterco (2:1); T6 = solo+substrato $(2: 1) ; \mathrm{T} 7=$ solo + areia $(1: 1) ; \mathrm{T} 8=$ solo. 
$\mathrm{Na}$ segunda etapa, avaliou-se o crescimento inicial das mudas de cedro-rosa em campo, utilizando-se os mesmos tratamentos e delineamento usados para a produção de mudas em casa de vegetação. As mudas foram plantadas em espaçamento de $3 \mathrm{~m} \times 3 \mathrm{~m}$, em covas de $30 \mathrm{~cm} \times 30 \mathrm{~cm} \times 30 \mathrm{~cm}$. Cada parcela foi constituída de uma planta, perfazendo as 32 parcelas. A definição da planta foi feita por meio da planta média, utilizando a altura como critério.

As avaliações ocorreram aos dois e cinco meses após o plantio em campo, sendo avaliada a altura total das plantas, o diâmetro do colo, o número de folhas por planta e o diâmetro da copa, medidos nos sentidos de maior e menor extensão, que foram utilizados para se obter a média.

Os dados foram submetidos à análise de variância (ANOVA) e as médias dos tratamentos foram comparadas pelo teste de Tukey a 5\% de probabilidade.

\section{Resultados e discussão}

$\mathrm{Na}$ primeira etapa, três meses após a semeadura, observou-se efeito do substrato sobre o crescimento em altura e número de folhas por mudas. $\mathrm{O}$ substrato solo+esterco (1:1) proporcionou maior crescimento em altura e número de folhas por planta, embora não tenha diferido estatisticamente, para as duas variáveis, dos substratos areia+solo+esterco $(1: 1: 1)$ e solo+esterco (2:1) e somente para altura de planta do substrato solo (Tabela 2). Esses substratos, exceto T8 (solo), apresentam-se entre os maiores valores para matéria orgânica, nutrientes $(\mathrm{Ca}, \mathrm{Mg}, \mathrm{K}, \mathrm{P}, \mathrm{N})$ e valores de CTC e $\mathrm{V} \%$, em função da presença em sua composição do esterco e do substrato comercial (Tabela 1).

A altura da parte aérea é uma característica de fácil medição e utilizada com eficiência para estimar o padrão de qualidade de mudas de espécies florestais em viveiros. Entretanto, para espécies nativas, os parâmetros adequados de altura ou outros, ainda não estão definidos para as diversas espécies utilizadas. Em cedro-rosa, Oliveira et al. (2008) encontraram altura média de 14,40 $\mathrm{cm}$ aos 95 dias após a semeadura, utilizando seis diferentes substratos, enquanto Roweder et al. (2012) observaram altura média de $6,8 \mathrm{~cm} \mathrm{e}$ $8,7 \mathrm{~cm}$ quando avaliaram Cedrela odorata em quatro diferentes substratos, aos 63 dias após a semeadura, em condição a pleno sol e com $50 \%$ de sombreamento, respectivamente.
Tabela 2. Altura de plantas $(\mathrm{H}) \mathrm{em} \mathrm{cm}$, e número de folhas por planta (NF) de cedro-rosa, em diferentes substratos, aos três meses de idade após semeadura, em casa de vegetação.

\begin{tabular}{ccl}
\hline Tratamentos & $\mathbf{H}(\mathbf{c m})$ & $\mathbf{N F}$ \\
\hline T1 & $9,2 \mathrm{ab}$ & $4,8 \mathrm{ab}$ \\
\hline T2 & $7,5 \mathrm{~b}$ & $4,0 \mathrm{bc}$ \\
T3 & $10,5 \mathrm{a}$ & $5,0 \mathrm{a}$ \\
T4 & $7,4 \mathrm{~b}$ & $3,8 \mathrm{c}$ \\
T5 & $8,6 \mathrm{ab}$ & $4,5 \mathrm{abc}$ \\
\hline T6 & $7,1 \mathrm{~b}$ & $4,0 \mathrm{bc}$ \\
T7 & $6,9 \mathrm{~b}$ & $4,0 \mathrm{bc}$ \\
\hline T8 & $8,2 \mathrm{ab}$ & $4,0 \mathrm{bc}$ \\
\hline Médias & 8,2 & 4,3 \\
\hline CV (\%) & 10,4 & 7,7 \\
\hline
\end{tabular}

$\mathrm{T} 1=$ areia + solo+esterco $(1: 1: 1) ; \mathrm{T} 2=$ areia + solo + substrato $(1: 1: 1) ; \mathrm{T} 3=$ solo+esterco $(1: 1) ; \mathrm{T} 4=$ solo+substrato $(1: 1)$; $\mathrm{T} 5=$ solo + esterco $(2: 1) ; \mathrm{T} 6=$ solo + substrato $(2: 1) ; \mathrm{T} 7=$ solo + areia (1:1); T8 = solo. Médias seguidas pela mesma letra na coluna não diferem estatisticamente entre si, pelo teste de Tukey a 5\%.

O tamanho médio das mudas de cedro-rosa aos 90 dias, considerando apenas os tratamentos com os melhores resultados (T1, T3, T4 e T8) foi de 9,1 cm, mas já apresentavam um bom indicativo dos melhores substratos para sua produção. Entretanto, como o tempo de permanência no viveiro é grande, os substratos, que servem de reserva de nutrientes, também devem apresentar características físicas, químicas e biológicas adequadas para o desenvolvimento da muda. O melhor tratamento, em número absoluto, solo+esterco (1:1) foi $52,2 \%$ superior ao pior tratamento, solo+areia (1:1) (Tabela 2). Observando a Tabela 1, constata-se que os valores de matéria orgânica e nutrientes para o tratamento solo+esterco $(1: 1)$ foi superior ao observado para o tratamento solo+areia (1:1). Trabalhando com omissão de nutrientes, Souza et al. (2009) obtiveram altura média de cedro-rosa de $13,2 \mathrm{~cm}$ para a planta controle e 23,6 cm quando utilizou solução completa de nutrientes, aos 110 dias após o plantio. Cherobini et al. (2008), obtiveram mudas de cedro-rosa com $14,7 \mathrm{~cm}$ aos 45 dias após a semeadura, para sementes provenientes de três localidades, semeadas em tubetes e usando substrato comercial Plantmax. Oliveira et al. (2008) conseguiram maior altura de planta, também para cedrorosa $(17,12 \mathrm{~cm}$, aos 95 dias após semeadura), utilizando substrato a base de casca de amendoim processada, húmus de minhoca, terra de barranco e areia. 
O número de folhas não é utilizado, normalmente, como característica de qualidade de mudas, mas pode agregar informações a outras características avaliadas. Nesse caso, os resultados do número de folhas foram concordantes com a altura de plantas e apenas o tratamento com solo (T8), não apresentou o mesmo comportamento.

Considerando apenas este período de avaliação, a recomendação mais prática seria a do tratamento solo + esterco (1:1) (T3), por resultar em maior altura de plantas, ser de fácil manejo (Tabela 2) e apresentar boas condições nutricionais e de matéria orgânica para o desenvolvimento das mudas (Tabela 1). Entretanto, nesse estádio as mudas ainda estão muito imaturas, necessitando de mais tempo para avaliação e destinação ao campo.

Com cinco meses, as mudas já estão prontas para serem levadas ao plantio em campo porque apresentam boa altura, bom diâmetro de caule e o sistema radicular já começa a extravasar o recipiente. Houve efeito significativo do uso de diferentes substratos para as características avaliadas, exceto para a relação altura/ diâmetro do caule (Tabela 3).

Para altura de plantas, aos cinco meses, os melhores resultados foram obtidos com os substratos areia+solo+esterco (1:1:1), solo+esterco (1:1) e solo+esterco (2:1). Entretanto, a diferença numérica dos dois primeiros substratos para o terceiro melhor, que não diferiram estatisticamente entre si, foi de cerca de $5 \mathrm{~cm}$ ou $13,6 \%$ e isso é importante considerar no momento da escolha final do substrato, tendo como base o maior crescimento da muda.
Em relação a todos os tratamentos, os diferentes substratos mostraram resultados bastante expressivos para altura de plantas. A diferença entre o substrato que proporcionou maior altura de plantas e aquele que proporcionou a menor altura foi de $24,8 \mathrm{~cm}$ ou $143 \%$ (Tabela 3). Estes substratos estão entre aqueles que possuem as melhores condições químicas para o desenvolvimento das mudas (Tabela 1), além de permitirem o aproveitamento pelas plantas pelo tempo de permanência no viveiro.

Gomes et al. (2002) trabalharam com Eucalyptus grandis, avaliando parâmetros morfológicos de mudas e consideraram a altura um atributo muito importante na estimativa do padrão de qualidade de mudas. Cunha et al. (2006) avaliaram o desenvolvimento de mudas de Acacia mangium e A. auriculiformis em diferentes substratos e verificaram maior altura de plantas quando cultivadas em substrato com adição de esterco bovino. Scalon et al. (2011), estudando o efeito de substratos constituídos por solo+areia $(1: 1)$ enriquecidos com adubo orgânico e químico obtiveram, 53 dias após a semeadura, maior altura de Caesalpinia ferrea em substrato de solo+areia (1:1) enriquecido com adubo orgânico nas doses de 14,69 e 19,46 $\mathrm{g} \mathrm{dm}^{-3}$. Trabalhando com jenipapo (Genipa americana) em diferentes substratos, em tubetes e sacos plásticos, Mesquita et al. (2011) obtiveram melhor resultado para altura de plantas, em tubetes, com solo+esterco+pó de coco (1:1:1) e solo+esterco+areia (1:1:1) e, em sacos plásticos, com solo+esterco+pó de coco (1:1:1).

Tabela 3. Altura (H), número de folhas (NF), diâmetro do colo (D), matéria seca da parte aérea (MPA), matéria seca da raiz (MR), relação altura/diâmetro do caule (H/D), relação altura/massa seca da parte aérea (H/MPA), relação massa seca da parte aérea/massa seca da raiz (MPA/MR) e índice de qualidade de Dickson (IQD) de mudas de cedro-rosa aos cinco meses após a semeadura, em casa de vegetação.

\begin{tabular}{ccccccccccc}
\hline Tratamento & $\mathbf{H}$ & $\mathbf{N F}$ & $\mathbf{D}$ & $\mathbf{M P A}$ & $\mathbf{M R}$ & $\mathbf{H} / \mathbf{D}$ & H/MPA & MPA/MR & IQD \\
T1 & $42,1 \mathrm{a}$ & $11,6 \mathrm{a}$ & $9,8 \mathrm{a}$ & $56,1 \mathrm{a}$ & $46,7 \mathrm{~b}$ & $4,4 \mathrm{a}$ & $0,75 \mathrm{c}$ & $1,20 \mathrm{~b}$ & $18,9 \mathrm{a}$ \\
\hline T2 & $31,7 \mathrm{~b}$ & $10,3 \mathrm{ab}$ & $7,3 \mathrm{~b}$ & $19,8 \mathrm{c}$ & $22,7 \mathrm{~d}$ & $4,4 \mathrm{a}$ & $1,61 \mathrm{~b}$ & $0,87 \mathrm{de}$ & $8,2 \mathrm{c}$ \\
T3 & $41,6 \mathrm{a}$ & $10,7 \mathrm{ab}$ & $9,4 \mathrm{a}$ & $50,0 \mathrm{~b}$ & $35,8 \mathrm{c}$ & $4,4 \mathrm{a}$ & $0,83 \mathrm{c}$ & $1,40 \mathrm{a}$ & $14,7 \mathrm{~b}$ \\
\hline T4 & $32,6 \mathrm{~b}$ & $9,4 \mathrm{bc}$ & $7,1 \mathrm{bc}$ & $13,4 \mathrm{de}$ & $14,7 \mathrm{e}$ & $4,6 \mathrm{a}$ & $2,46 \mathrm{a}$ & $0,91 \mathrm{~d}$ & $5,1 \mathrm{c}$ \\
T5 & $36,7 \mathrm{ab}$ & $9,9 \mathrm{abc}$ & $8,9 \mathrm{ab}$ & $50,1 \mathrm{~b}$ & $49,1 \mathrm{a}$ & $4,2 \mathrm{a}$ & $0,72 \mathrm{c}$ & $1,03 \mathrm{c}$ & $19,4 \mathrm{a}$ \\
\hline T6 & $29,6 \mathrm{~b}$ & $10,3 \mathrm{ab}$ & $7,2 \mathrm{~b}$ & $15,8 \mathrm{~d}$ & $20,7 \mathrm{~d}$ & $4,1 \mathrm{a}$ & $1,87 \mathrm{~b}$ & $0,76 \mathrm{ef}$ & $7,5 \mathrm{c}$ \\
\hline T7 & $17,3 \mathrm{c}$ & $6,7 \mathrm{~d}$ & $5,2 \mathrm{~cd}$ & $6,1 \mathrm{f}$ & $10,5 \mathrm{f}$ & $3,4 \mathrm{a}$ & $2,85 \mathrm{a}$ & $0,58 \mathrm{~g}$ & $4,2 \mathrm{c}$ \\
\hline T8 & $21,1 \mathrm{c}$ & $7,9 \mathrm{~cd}$ & $5,0 \mathrm{~d}$ & $10,9 \mathrm{e}$ & $14,5 \mathrm{e}$ & $4,2 \mathrm{a}$ & $1,95 \mathrm{~b}$ & $0,75 \mathrm{f}$ & $5,2 \mathrm{c}$ \\
\hline Médias & 31,6 & 9,6 & 7,5 & 27,8 & 26,8 & 4,2 & 1,63 & 0,94 & 10,4 \\
\hline CV $\%$ & 10,3 & 8,9 & 11,1 & 4,1 & 3,5 & 15,4 & 12,16 & 5,15 & 16,4 \\
\hline
\end{tabular}

$\mathrm{T} 1=\operatorname{areia}+\operatorname{solo}+$ esterco $(1: 1: 1) ; \mathrm{T} 2=\operatorname{areia}+$ solo + substrato $(1: 1: 1) ; \mathrm{T} 3=$ solo+esterco $(1: 1) ; \mathrm{T} 4=$ solo+substrato $(1: 1) ; \mathrm{T} 5=$ solo+esterco $(2: 1) ; \mathrm{T} 6=$ solo+substrato $(2: 1) ; \mathrm{T} 7=$ solo+areia $(1: 1) ; \mathrm{T} 8=$ solo. Médias seguidas pela mesma letra na coluna não diferem estatisticamente entre si, pelo teste de Tukey a 5\%. 
Segundo estes autores o substrato solo+esterco não atendeu às exigências nutricionais da espécie em viveiro.

Para Caesalpinia pyramidalis, Dantas et al. (2011) obtiveram maior altura de plantas com substrato comercial, enquanto o pior resultado foi obtido com a presença de esterco no substrato (solo+areia+esterco). Maranho \& Paiva (2011) encontraram maior altura de Senna silvestris, em média $18,8 \mathrm{~cm}$, aos 90 dias após repicagem para o substrato comercial Plantmax. Roweder et al. (2012) encontraram maior altura de planta de Cedrela odorata com húmus de minhoca. Outros resultados favoráveis para este substrato também foram encontrados para Moringa oleifera (Bezerra et al., 2004), Luehea divaricata (Grave et al., 2007) e Handroanthus impetiginosus (Sabonaro \& Galbiatti, 2007).

O maior número de folhas por planta aos cinco meses foi verificado no tratamento com areia + solo+esterco (1:1:1), mas não diferiu estatisticamente dos tratamentos T2, T3, T5 e T6. Menor número de folhas foi encontrado nos tratamentos T7 e T8 (Tabela 3), que são os únicos substratos testados que não receberam nenhum tipo de material orgânico em sua composição (Tabela 1).

O maior diâmetro de caule foi observado nos tratamentos areia + solo+esterco $(1: 1: 1)$ e solo+esterco (1:1), quando analisado aos cinco meses. Para essa variável, os piores valores também foram obtidos com os tratamentos T7 e T8 (Tabela 3), indicando que a presença de material orgânico no substrato pode ser decisivo para o crescimento e manutenção das mudas durante seu tempo em viveiro. Roweder et al. (2012) encontraram maior valor de diâmetro do caule, em Cedrela odorata, com os substratos de composto vegetal e húmus de minhoca, enquanto Oliveira et al. (2008), encontraram, em Cedrela fissilis Vell., o pior resultado para diâmetro do caule com o uso de substrato a base de casca de arroz carbonizada (50\%) e esterco de galinha $(40 \%)$.

A maior massa seca da parte aérea foi obtida com o tratamento areia+solo+esterco (1:1:1) (T1) aos cinco meses. Os tratamentos solo+esterco (1:1) (T3) e solo+esterco (2:1) (T5), apesar de diferirem estatisticamente do tratamento T1, mostraram uma diferença aproximada de apenas $12 \%$. Entretanto, o valor médio para todos os demais tratamentos foi bem baixo, $425 \%$ inferior ao tratamento areia + solo+esterco (1:1:1) (Tabela 3). Roweder et al. (2012) encontraram maior massa seca da parte aérea de Cedrela odorata com o uso do húmus de minhoca.
De modo semelhante, a maior massa seca de raiz também foi verificada para os mesmos três tratamentos (T1, T3 e T5), mudando apenas a ordem de maior massa. Assim, o maior valor foi observado para o tratamento solo+esterco (2:1), seguido dos tratamentos areia+solo+esterco (1:1:1) e solo+esterco (1:1), todos diferindo estatisticamente entre si. Os menores valores de massa seca de raiz foram encontrados para os tratamentos solo+areia (1:1) e apenas solo (Tabela 3 ). Maranho \& Paiva (2011) conseguiram maior massa seca de parte aérea e de raiz em mudas de Senna silvestris quando utilizaram plantmax como substrato. Por outro lado, Roweder et al. (2012) verificaram o pior desempenho para massa seca da raiz de Cedrela odorata com o uso dos substratos casca de coco e plantmax. Oliveira et al. (2008) não encontraram efeito de substratos para massa seca de raiz de Cedrela fissilis Vell.

Considerando todas as características quantitativas de avaliação das mudas no momento de disponibilizálas para o plantio em campo, percebe-se que os melhores substratos foram areia+solo+esterco (1:1:1), solo+esterco (2:1) e solo+esterco (1:1) (Tabela 3). O uso de qualquer um desses substratos permite a obtenção de bons resultados em crescimento da planta, tanto em altura das mudas, como para maior número de folhas, crescimento do diâmetro do colo e maior massa seca da parte aérea e raiz. Para mangabeira, Dias et al. (2010) verificaram que os substratos contendo terra vegetal $(50 \%)+$ casca de arroz carbonizada $(50 \%)+$ superfosfato simples $\left(1,5 \mathrm{~kg} \mathrm{~m}^{-3}\right)$ e terra vegetal $(80 \%)+$ fibra de coco $(20 \%)+$ superfosfato simples $\left(1,5 \mathrm{~kg} \mathrm{~m}^{-3}\right)$ proporcionam as melhores condições físico-hídricas para o crescimento das mudas em altura e diâmetro caulinar. Já Cunha et al. (2006) conseguiram melhor performance de mudas de Acacia mangium e A. auriculiformis quando utilizaram esterco bovino na composição do substrato.

Para a qualidade de mudas, considerando a relação da altura da parte aérea pelo peso da matéria seca da parte aérea, verificou-se que os menores índices foram obtidos para os tratamentos solo+esterco $(2: 1)$, areia+solo+esterco (1:1:1) e solo+esterco (1:1) (Tabela 3). De acordo com Gomes \& Paiva (2012), quanto menor esse índice, mais lenhificada será a muda e maior deverá ser sua capacidade de sobrevivência no campo.

Avaliando a relação da matéria seca da parte aérea pela matéria seca das raízes, os maiores índices foram encontrados em ordem e estatisticamente diferentes para 
os tratamentos solo+esterco (1:1), areia + solo+esterco (1:1:1) e solo+esterco (2:1), porém, todos ficaram abaixo de 2,0 (Tabela 3), que de acordo com Gomes \& Paiva (2012), é o valor que estabelece o melhor índice para essa relação. Ainda, segundo estes autores, quanto maior for o índice de qualidade de Dickson (IQD), melhor será o padrão de qualidade de mudas. Os maiores valores para esse índice foram verificados para os tratamentos solo+esterco (2:1) e areia+solo+esterco (1:1:1), que não diferiram estatisticamente entre si, seguido pelo tratamento solo+esterco $(1: 1)$. Esses valores foram, em média, 292\% superiores aos índices verificados para os demais tratamentos (Tabela 3). Bernardino et al. (2005) estudaram a influência da saturação por bases em diferentes solos sobre o IQD de mudas de angicovermelho e verificaram que os tratamentos influenciaram o índice, sendo o maior valor de 18,32. Já Maranho \& Paiva (2012) conseguiram maior IQD para mudas de Physocalymma scaberrimum Pohl quando utilizaram substratos com $100 \%$ de resíduo de açaí.

Dessa forma, os índices que determinam a qualidade das mudas confirmam os resultados quantitativos utilizados para avaliar o crescimento das mesmas, indicando que os tratamentos citados anteriormente, areia+solo+esterco (1:1:1), solo+esterco (2:1) e solo+esterco (1:1), são os mais adequados para a produção de mudas de cedro-rosa em viveiro.

De modo geral, todos os substratos que resultaram em efeito benéfico para as mudas foram aqueles que possuíam boas condições químicas, em relação aos teores de matéria orgânica, nutrientes e valores de CTC e V\% (Tabela 1).

Dois meses após o plantio, em campo, verificouse que houve diferença estatística para todas as características avaliadas (Tabela 4). Nesta idade, as melhores características de mudas trazidas do viveiro ainda se mostram bastante determinantes, uma vez que as melhores características quantitativas em campo foram idênticas às verificadas em viveiro.

Assim, o maior crescimento inicial em altura de mudas de cedro-rosa em campo foi verificado para os tratamentos solo+esterco $(2: 1)$ e solo+esterco (1:1), que não diferiram estatisticamente entre si, seguido do tratamento areia + solo+esterco (1:1:1). Houve um incremento superior em altura no crescimento inicial das mudas em campo quando comparado ao viveiro, uma vez que, em média, esses três tratamentos apresentaram altura 59\% superior as médias dos demais tratamentos em campo e $51 \%$ superior em viveiro (Tabela 4 ).
Tabela 4. Altura de plantas (H), número de folhas (NF), diâmetro do colo (D) e relação altura/diâmetro do colo (H/D) de plantas de cedro-rosa aos dois meses após plantio em campo.

\begin{tabular}{ccccc}
\hline Tratamentos & $\mathbf{H}(\mathbf{c m})$ & $\mathbf{N F}$ & $\mathbf{D}(\mathbf{m m})$ & $\mathbf{H} / \mathbf{D}$ \\
\hline T1 & $48,3 \mathrm{~b}$ & $12,4 \mathrm{ab}$ & $15,4 \mathrm{a}$ & $3,1 \mathrm{ab}$ \\
\hline T2 & $35,3 \mathrm{~cd}$ & $10,0 \mathrm{abc}$ & $11,6 \mathrm{~b}$ & $3,0 \mathrm{ab}$ \\
T3 & $56,0 \mathrm{a}$ & $13,7 \mathrm{a}$ & $15,5 \mathrm{a}$ & $3,6 \mathrm{ab}$ \\
\hline T4 & $38,8 \mathrm{c}$ & $9,7 \mathrm{bc}$ & $10,3 \mathrm{~b}$ & $3,8 \mathrm{ab}$ \\
T5 & $59,4 \mathrm{a}$ & $13,0 \mathrm{ab}$ & $15,7 \mathrm{a}$ & $3,8 \mathrm{a}$ \\
T6 & $34,7 \mathrm{~cd}$ & $8,5 \mathrm{c}$ & $12,2 \mathrm{~b}$ & $2,9 \mathrm{~b}$ \\
\hline T7 & $30,4 \mathrm{~d}$ & $8,3 \mathrm{c}$ & $7,7 \mathrm{c}$ & $4,0 \mathrm{a}$ \\
T8 & $32,4 \mathrm{~cd}$ & $10,3 \mathrm{abc}$ & $10,0 \mathrm{bc}$ & $3,3 \mathrm{ab}$ \\
\hline Médias & 41,9 & 10,7 & 12,3 & 3,4 \\
\hline CV $(\%)$ & 6,8 & 14,7 & 8,3 & 11,3 \\
\hline
\end{tabular}

$\mathrm{T} 1=$ areia + solo+esterco $(1: 1: 1) ; \mathrm{T} 2=$ areia + solo + substrato $(1: 1: 1) ; \mathrm{T} 3=$ solo+esterco $(1: 1) ; \mathrm{T} 4=$ solo+substrato $(1: 1)$; $\mathrm{T} 5=$ solo+esterco $(2: 1) ; \mathrm{T} 6=$ solo + substrato $(2: 1) ; \mathrm{T} 7=$ solo + areia $(1: 1) ; \mathrm{T} 8=$ solo. Médias seguidas pela mesma letra na coluna não diferem estatisticamente entre si, pelo teste de Tukey a 5\%.

O número de folhas não apresenta a mesma relação comparada às demais características, já que a maior quantidade de folhas foi observada em ordem e sem diferença estatística entre as mesmas, para os tratamentos T3, T8, T5, T1 e T2 (Tabela 4).

Os maiores valores para diâmetro do colo foram verificados nos tratamentos solo+esterco $(2: 1)$, solo+esterco (1:1) e areia+solo+esterco (1:1:1), sem diferença estatística entre os mesmos. Esses valores seguiram a mesma dinâmica de crescimento em altura (Tabela 4).

A relação entre a altura das mudas e o seu diâmetro constitui importante parâmetro morfológico para estimar o crescimento das mesmas após o plantio definitivo no campo, indicando um equilíbrio de crescimento, também denominado de quociente de robustez. Quanto menor seu valor, maior será a capacidade das mudas sobreviverem e se estabelecerem na área definitiva (Gomes \& Paiva, 2012). Os tratamentos apresentaram valores muito próximos entre si, sendo que o menor valor foi observado para T6, mas não diferiu estatisticamente dos tratamentos T1, T2, T3, T4 e T8. Não foi possível, portanto, determinar nessa fase do estabelecimento das mudas qual a melhor relação entre a altura de plantas e o diâmetro do caule (Tabela 4). 
Cinco meses após o plantio em campo, observa-se que todas as características avaliadas apresentaram diferença estatística (Tabela 5).

Tabela 5. Altura de plantas $(\mathrm{H})$, número de folhas (NF), diâmetro do colo (D), diâmetro da copa (Dc) e relação altura/ diâmetro do colo (H/D) de plantas de cedro-rosa aos cinco meses após plantio em campo.

\begin{tabular}{cccccc}
\hline Tratamentos & $\mathbf{H}(\mathbf{c m})$ & $\mathbf{N F}$ & $\mathbf{D}(\mathbf{m m})$ & $\mathbf{D c}(\mathbf{c m})$ & $\mathbf{H} / \mathbf{D}$ \\
\hline T1 & $65,7 \mathrm{a}$ & $5,8 \mathrm{~d}$ & $27,7 \mathrm{~b}$ & $91,5 \mathrm{~b}$ & $2,4 \mathrm{~A}$ \\
T2 & $41,0 \mathrm{bc}$ & $6,8 \mathrm{~cd}$ & $18,5 \mathrm{c}$ & $69,1 \mathrm{~d}$ & $2,2 \mathrm{~A}$ \\
T3 & $57,1 \mathrm{a}$ & $8,8 \mathrm{a}$ & $27,6 \mathrm{~b}$ & $62,3 \mathrm{e}$ & $2,1 \mathrm{~A}$ \\
T4 & $41,2 \mathrm{bc}$ & $4,3 \mathrm{e}$ & $18,5 \mathrm{c}$ & $35,1 \mathrm{~g}$ & $2,2 \mathrm{~A}$ \\
T5 & $60,7 \mathrm{a}$ & $9,0 \mathrm{a}$ & $33,8 \mathrm{a}$ & $74,5 \mathrm{~d}$ & $1,8 \mathrm{Ab}$ \\
T6 & $45,8 \mathrm{~b}$ & $8,3 \mathrm{ab}$ & $31,7 \mathrm{ab}$ & $101,8 \mathrm{a}$ & $1,4 \mathrm{~B}$ \\
T7 & $41,0 \mathrm{bc}$ & $7,5 \mathrm{bc}$ & $30,4 \mathrm{ab}$ & $82,9 \mathrm{c}$ & $1,3 \mathrm{~B}$ \\
\hline T8 & $34,8 \mathrm{c}$ & $7,3 \mathrm{bc}$ & $19,6 \mathrm{c}$ & $53,1 \mathrm{~F}$ & $1,8 \mathrm{ab}$ \\
\hline Médias & 48,4 & 7,2 & 26,0 & 71,3 & 1,9 \\
\hline CV (\%) & 9,4 & 6,2 & 7,0 & 3,2 & 13,9 \\
\hline
\end{tabular}

$\mathrm{T} 1$ - areia + solo+esterco $(1: 1: 1) ; \mathrm{T} 2$ - areia + solo+substrato $(1: 1: 1)$; T3 - solo+esterco (1:1); T4 - solo+substrato (1:1); T5 - solo+esterco (2:1); T6 - solo+substrato $(2: 1)$; T7 - solo+areia (1:1) e T8 solo. Médias seguidas pela mesma letra na coluna não diferem estatisticamente entre si, pelo teste de Tukey a $5 \%$.

Assim, observa-se que os substratos utilizados na produção das mudas de cedro-rosa em viveiro influenciaram o crescimento inicial das mudas em campo, entretanto, com o passar do tempo essas diferenças reduziram. No início do crescimento em campo, a altura das plantas e o diâmetro do caule se mantiveram praticamente na mesma forma de crescimento observado em viveiro.

A altura das plantas continua apresentando o mesmo comportamento de crescimento observado em viveiro, com os maiores valores encontrados para os tratamentos areia + solo+esterco $(1: 1: 1)$, solo+esterco $(2: 1)$ e solo+esterco (1:1), sem diferença estatística entre os mesmos. Entretanto, já começa ocorrer uma redução da altura da média desses três tratamentos, com os demais, passando agora para 50\% (Tabela 5).

O maior número de folhas foi observado para os tratamentos T5, T3 e T6, sem diferença estatística entre os mesmos (Tabela 5).

O diâmetro de caule foi a variável que sofreu maior alteração após o plantio em campo. Os maiores valores foram verificados para os tratamentos solo+esterco $(2: 1)$, solo+substrato (2:1) e solo+areia (1:1), seguidos pelos tratamentos areia+solo+esterco $(1: 1: 1)$ e solo+esterco $(1: 1)$. Os tratamentos solo+areia (1:1) e solo+substrato (2:1) foram os que apresentaram maior incremento em diâmetro do caule, com $295 \%$ e $160 \%$, respectivamente, em relação ao primeiro período de avaliação em campo (Tabela 5).

O maior diâmetro de copa foi verificado para o tratamento solo+substrato $(2: 1)$, seguido do tratamento areia + solo+esterco (1:1:1) e solo+areia (1:1), todos distintos estatisticamente entre si. Os tratamentos solo+areia (1:1) e solo+substrato (2:1) que apresentaram maior incremento do diâmetro do caule também se encontram entre os que apresentaram maior diâmetro de copa (Tabela 5).

A relação entre altura e diâmetro do caule, que é um bom indicador para estimar o crescimento das mudas após o plantio definitivo em campo, foi favorável para os tratamentos que utilizaram solo+areia (1:1) e solo+substrato (2:1) em viveiro, os quais apresentaram os menores índices dessa relação (Tabela 5).

Paiva \& Poggiani (2000) verificaram, em um ano, entre cinco espécies vegetais, que o cedro-rosa apresentou maior crescimento inicial em diâmetro, com 5,9 mm e o segundo maior crescimento em altura, perdendo apenas para o angico, com 25,6 cm.

\section{Conclusões}

O melhor crescimento e qualidade de mudas de cedro-rosa produzidas em viveiro foram obtidos com os tratamentos areia + solo+esterco (1:1:1), solo+esterco (2:1) e solo+esterco (1:1).

Os substratos utilizados na produção de mudas em viveiro influenciam o crescimento inicial de mudas de cedro-rosa em campo, sendo que os melhores resultados observados para o crescimento em altura e diâmetro do colo em viveiro, se mantém após o plantio em campo.

\section{Referências}

BERNARDINO, D. C. S.; PAIVA, H. N.; NEVES, J. C. L.; GOMES, J. M.; MARQUES, V. B. Crescimento e qualidade de mudas de Anadenanthera macrocarpa (Benth) Brenan em resposta a saturação por bases do substrato. Revista Árvore, Viçosa, MG, v. 29, n. 6, p. 863-870, 2005.

BEZERRA, A. M. E.; MOMENTÉ, V. G.; MEDEIROS FILHO, S. Germinação de sementes e desenvolvimento de plântulas de moringa (Moringa oleifera Lam.) em função do peso da semente e do tipo de substrato. Horticultura Brasileira, Brasília, DF, v. 22, n. 2, p. 295-299, 2004. 
CAIRES, S. M.; FONTES, M. P. F.; FERNANDES, R. B. A.; NEVES, J. C. L.; FONTES, R. L. F. Desenvolvimento de mudas de cedro-rosa em solo contaminado com cobre: tolerância e potencial para fins de fitoestabilização do solo. Revista Árvore, Viçosa, MG, v. 35, n. 6 , p. 1181-1188, 2011.

CARVALHO, P. E. R. Espécies florestais brasileiras: recomendações silviculturais, potencialidades e uso da madeira. Colombo: EMBRAPA-CNPF; Brasília, DF: EMBRAPA-SPI, 1994. $639 \mathrm{p}$.

CHEROBINI, E. A. I.; MUNIZ, M. F. B.; BLUME, E. Avaliação da qualidade de sementes e mudas de cedro. Ciência Florestal, Santa Maria, RS, v. 18, n. 1, p. 65-73, 2008.

CUNHA, A. M.; CUNHA, G. M.; SARMENTO, R. A.; CUNHA. G. M.; AMARAL, J. F. T. Efeito de substratos sobre o desenvolvimento de mudas de Acacia sp. Revista Árvore, Viçosa, MG, v. 30, n. 2 , p. $207-214,2006$.

CUNHA, A. O.; ANDRADE, L. A.; BRUNO, R. L. A.; SILVA, J. A. L.; SOUZA, V. C. Efeitos de substratos e das dimensões dos recipientes na qualidade das mudas de Tabebuia impetiginosa (Mart. ex D.C.) Standl. Revista Árvore, Viçosa, MG, v. 29, n. 4, 2005.

DANNER, M. A.; CITADIN, I.; FERNANDES JUNIOR, A. A.; ASSMANN, A. P.; MAZARO, S. M.; SASSO, S. A. Z. Formação de mudas de jabuticabeira (Plinia sp.) em diferentes substratos e tamanhos de recipientes. Revista Brasileira de Fruticultura, Jaboticabal, v. 29, n. 1, p. 179-182, 2007.

DANTAS, B. F.; LOPES, A. P.; SILVA, F. F. S.; BATISTA, P. F.; PIRES, M. M. M. L.; ARAGÃO, C. A. Produção de mudas de catingueira-verdadeira (Caesalpinia pyramidalis Tul.) em função de substratos e luminosidades. Científica, Jaboticabal, v. 39, p. 1/2, p. 34-43, 2011.

DIAS, T. J.; FERREIRA, C. S.; SOUZA, V. A. B.; FREIRE, J. L. O.; PEREIRA, W. E. Diferentes composições de substratos no crescimento de mudas de genótipos de mangabeira (Hancornia speciosa Gomes). Engenharia Ambiental, Espírito Santo do Pinhal, v. 7, n. 3, p. 92-107, 2010.

DICKSON, A.; LEAF, A. L.; HOSNER, J. F. Quality appraisal of White spruce and White pine seedling stock in nurseries. Forest Chronicle, v. 36, p. 10-13, 1960.

FERREIRA, M. G. R.; ROCHA, R. B.; GONÇALVES, E. P.; ALVES, E. U.; RIBEIRO, G. D. Influência do substrato no crescimento de mudas de cupuaçu (Theobroma grandiflorum Schum.). Acta Scientiarum Agronomy, Maringá, v. 31, n. 4, p. 677-681, 2009.

GOMES, J. M.; COUTO, L.; LEITE, H. G.; XAVIER, A.; GARCIA, S. L. R. Parâmetros morfológicos na avaliação da qualidade de mudas de Eucalyptus grandis. Revista Árvore, Viçosa, MG, v. 26, n. 6, p. 655-664, 2002.

GOMES, J. M.; PAIVA, H. N. Viveiros florestais: propagação sexuada. Viçosa, MG: Ed. da UFV, 2012.

GRAVE, F.; FRANCO, E. T. H.; PACHECO, J. P.; SANTOS, S. R. Crescimento de plantas jovens de Açoita-cavalo em quatro diferentes substratos. Ciência Florestal, Santa Maria, RS, v. 17, n. 4, p. 289298, 2007.
KÄMPF, A. N. Seleção de materiais para uso como substrato. In: KÄMPF, A. N.; FIRMINO, M. H. Substratos para plantas: a base da produção vegetal em recipientes. Porto Alegre: Genesis, 2000. p. 209-215.

LORENZI, H. Árvores brasileiras: manual de identificação e cultivo de plantas arbóreas nativas do Brasil. Nova Odessa: Plantarum, 1992.

MARANHO, A. S.; PAIVA, A. V. Crescimento inicial de mudas de Senna silvestris (Vell.) H. S. Irwin \& Barneby cultivadas em diferentes substratos. Revista da Sociedade Brasileira de Arborização Urbana, Piracicaba, v. 6, n. 4, p. 1-14, 2011.

MARANHO, A. S.; PAIVA, A. V. Produção de mudas de Physocalymma scaberrimum em substratos compostos por diferentes porcentagens de resíduo orgânico de açaí. Floresta, Curitiba, v. 42, n. 2, p. 399-408, 2012.

MESQUITA, J. B.; SANTOS, M. J. C.; RIBEIRO, G. T.; MOURA, A. O. Avaliação da composição de substratos e recipientes na produção de mudas de jenipapo (Genipa americana L.). Natural Resources, Aquidabã, v. 1, n. 1, p. 37-45, 2011.

OLIVEIRA, R. B.; LIMA, J. S. S.; SOUZA, C. A. M.; SILVA, S. A.; MARTINS FILHO, S. Produção de mudas de essências florestais em diferentes substratos e acompanhamento do desenvolvimento em campo. Ciência e Agrotecnologia, Lavras, v. 32, n. 1, p. 122128, 2008.

PAIVA, A. V.; POGGIANI, F. Crescimento de mudas de espécies arbóreas nativas plantadas no sub-bosque de um fragmento florestal. Scientia Florestalis, Piracicaba, n. 57, p. 141-151, 2000.

RÊGO, G. M.; POSSAMAI, E. Efeito do substrato e da temperatura sobre a germinação e vigor de sementes do jequitibá-rosa (Cariniana legalis). Colombo: Embrapa Florestas, 2004. (Embrapa Florestas. Comunicado técnico, 127).

ROWEDER, C.; NASCIMENTO, M. S.; SILVA, J. B. Uso de diferentes substratos e ambiência na germinação e desenvolvimento inicial de plântulas de cedro. Pesquisa Aplicada \& Agrotecnologia, Guarapuava, v. 5, n. 1, p. 27-46, 2012.

SABONARO, D. Z.; GALBIATTI, J. A. Efeito de níveis de irrigação em substratos para a produção de mudas de ipê-roxo. Scientia Forestalis, Pircicaba, n. 74, p. 95-102, 2007.

SCALON, S. P. Q.; TEODÓSIO, T. K. C.; NOVELINO, J. O.; KISSMANN, C.; MOTA, L. H. S. Germinação e crescimento de Caesalpinia ferrea Mart. ex Tul. em diferentes substratos. Revista Árvore, Viçosa, MG, v. 35, n. 3, p. 633-639, 2011. Edição especial.

STEFANO, M. V.; CALAZANS, L. S. B.; SAKURAGUI, C.M. Meliaceae. In: JARDIM BOTÂNICO DO RIO DE JANEIRO. Lista de espécies da flora do Brasil. Rio de Janeiro, 2014. Disponível em: $<$ http://floradobrasil.jbrj.gov.br/jabot/floradobrasil/FB162>. Acesso em: 13 Ago. 2014

SOUZA, P. A.; VENTURIN, N.; MACEDO, R. L. G.; VENTURIN, R. P.; TUCCI, C. A. F.; CARLOS, L. Nutritional assessment of cedar seedlings (Cedrela fissilis Vell.) grown in a greenhouse. Cerne, Lavras, v. 15, n. 2, p. 236-243, 2009. 
